\title{
Effect of Fiber Loading and Alkali Treatment on Rice Straw Fiber Reinforced Composite for Automotive Bumper Beam Application
}

\author{
Andi Saidah", Sri Endah Susilowati ${ }^{\#}$, Yos Nofendri ${ }^{\#}$ \\ ${ }^{\#}$ Department of Mechanical Engineering, Faculty of Engineering, Universitas 17 Agustus 1945 Jakarta, Jakarta 14350, Indonesia. \\ E-mail:andi.saidah@uta45jakarta.ac.id; sriendah.susilowati@yahoo.com; yosnofendri@gmail.com
}

\begin{abstract}
Natural fiber-reinforced composites (NFC) comprise the principal subject for the wide-ranging research in the material industries with lower costs. The use of rice straw as the reinforcement material for polymer composites intended for car bumper application is reported. This study was aimed to evaluate the composite mechanical properties of tensile and impact strength, as well as the microscopic structures, under the alkali treatment of $\mathrm{NaOH}$ and $10,20,30$ and $40 \%$ (v/v) fiber loading variations. The results showed that the mechanical properties of alkali-treated composites were improved relative to the untreated fiber-reinforced composites. The highest tensile strength was observed at $14.75 \mathrm{MPa}$ together with the highest impact strength at $23.52 \mathrm{~J} \mathrm{~cm}^{-1}$ for the alkali-treated and $30 \%$ fiber loading composites. This makes the rice straw fiber-reinforced composites at $30 \%$ fiber loading competitive against the standard commercial bumper with a maximum tensile strength of 8.08 MPa and impact strength of $23.31 \mathrm{~J}$ cm-1. The precise claim of alkali conduct with sodium hydroxide indicates the improvement of tensile and impact strength of the RSF-reinforced composites. This study also shows fiber loading provides various mechanical properties of the composites. The rice straw fiber, at $30 \%$ fiber loading attached with the alkali treatment comprises an alternative material to reinforce a polymer composite for automotive bumper application with a viable tensile and effect strong point against a marketable bumper.
\end{abstract}

Keywords — rice straw; alkali treatment; fiber loading; automotive bumper; natural fiber composite.

\section{INTRODUCTION}

Natural Fiber-Reinforced Composites (NFC) are among the leading subject for the extensive research in the material industries to lower costs and profit margins [1]. The driving force behind the research is the inexpensive cost of natural fibers, recyclability, and the desirability of green products [2]. Also, the properties of the NFC that are light in weight, low in density, strong, resistant to corrosion, with a high degree of flexibility and less machine tool wear during machining [2]-[6]. The life cycle assessment for NFC compared to glass fiber composites, also showed that they have lower environmental impacts, higher fiber content for equivalent performance, and better end-of-life incineration that results in recovered energy and carbon credit [7].

In the automotive industry, NFC applications demand a good quality on mechanical properties, particularly impact strength, flexural properties, ultimate breaking force, processing suitability, and crash behavior [8]. The uses of NFC have also been proven to be viable for more than a decade in a certain number of automotive parts $[4,8]$. The research for automotive applications is for most of the time involved the systematic selection of NFC materials and the tests of their mechanical properties, such as tensile strength, impact strength, Young's modulus, and flexural properties [9], [10].

Numerous studies have indicated fiber loading as one of the main factors that significantly influence the quality of a composite. Studies towards the physical and mechanical properties were majored not only in the observations of tensile and flexural strengths [11]-[14], but also extended to thermal properties and chemical resistance [15]. In the application of natural fibers, various loading range has a wide range of response conforming to its source. The reason could be varied conditional to the experimental parameters, but one major reason is the reduction in the fiber-matrix adhesion [16].

Aside of the fiber loading, natural fibers have a lignin (wax) layer that is found throughout the fiber surface that causes poor bonding between the fibers and the matrix [1-6, 17]. This makes the adoption of the natural fibers take a detour by the needs of modifying the fibers for better engagement with the matrix. The aim is to improve the adhesion between the fiber surface and the polymer matrix, as well as increasing fiber strength [5], [8], [18]. The current observed trend for the modification of the natural fiber favors chemical modification (alkaline, silane, permanganate, peroxide, isocyanate, acetylation, acrylonitrile grafting, and malleated coupling treatment) over physical modification [2], 
[19] and the alkali treatment is one of the most used chemical treatment for natural fibers. Typical chemicals used for alkali pretreatment are sodium hydroxide $(\mathrm{NaOH})$ and potassium hydroxide $(\mathrm{KOH})$ [20]. However, the former was found to be more superior in terms of effectiveness for biomass solubilization [21]. $\mathrm{NaOH}$ has been used to remove the hydrogen bonding in the network structure of fibers, thus increasing fiber's surface roughness [5], [6], [22]. Many studies have been emphasizing the improvement on mechanical properties of composites after treating the fibers with $\mathrm{NaOH}$ [3], [23]-[25].

Abundant sources for natural fibers are available for further exploration, and rice straw is one from many sources of natural fibers that have been widely tested for composite applications [23]-[24], [26]-[30] . Rice straw has been investigated for its utilization in cement-based composites [27] and natural filler for injection-molded high-density polyethylene (HDPE) [29]. An optimization effort has also been conducted to achieve the possible highest impact strength for polymer composites application [28], [31].

Based on our literature research, the use of rice straw for polymer composites reinforcement in the automotive industry is scarcely reported. This study aims to evaluate the mechanical properties of tensile and impact strength on rice straw fiber-reinforced polymer composite for automotive bumper applications. The effect of fiber loading was evaluated where raw (untreated) and alkali-treated fibers were used as reinforcement materials. Parameters such as tensile strength, impact strength, as well as microscopic structure observation were determined to identify the range of the fiber loading that produces polymer composites with the said quality equal to or above a standard commercial polymer bumper.

\section{MATERIALS AND MethodS}

\section{A. Materials}

Rice Straw Fibers (RSF) from the stem of Asian rice plants (Oryza sativa) were collected from the South Province of Sulawesi, Indonesia. The straws with a minimum length of $270 \mathrm{~mm}$ were selectively chosen for the further cleansing process from dirt and impurities. The cleaned fibers were then cut into an average size of $20 \mathrm{~mm}$ in length and $4.5 \mathrm{~mm}$ in width. Air-tight plastic containers were used to store the RSF to prevent water absorption and microbial attack towards the fibers. The chemical composition of RSF that covers lignin, cellulose, and hemicellulose, as well as the mechanical properties of the fibers can be seen from Table 1 .

TABLE I

CHEMICAL COMPONENT OF RICE STRAW [26], [32], [32]-[36] AND THE MECHANICAL PROPERTIES OF RICE STRAW [30], [32], [37]

\begin{tabular}{|l|c|}
\hline \multicolumn{1}{|c|}{ Component/Properties } & Value (Range) \\
\hline Cellulose (wt.\% dry) & $24.0-48.0$ \\
\hline Hemicellulose (wt.\% dry) & $21.5-28.0$ \\
\hline Lignin (wt.\% dry) & $4.0-9.9$ \\
\hline Water content (wt.\% wet) & $6.8-88$ \\
\hline Volatiles (wt.\% daf) & $80.1-98.2$ \\
\hline Density $\left(\mathrm{g} \mathrm{m}^{-3}\right)$ & $0.86-0.87$ \\
\hline Young's modulus $(\mathrm{GPa})$ & $24.67-65$ \\
\hline Tensile strength $(\mathrm{MPa})$ & $435-450$ \\
\hline
\end{tabular}

The bio-composite matrix was made from the mixture of low viscosity thixotropic variant epoxy resin (ADR246TX, Adhesive Technologies NZ Ltd) with a density of $1.2 \mathrm{~g} \mathrm{~cm}-3$, Young's modulus at 2.7 GPa, and Poisson's ratio of 0.4, and epoxy hardener (JN Duo Component Epoxy Adhesive) at the ratio of 1:1. A polymer car bumper from one of the types of low-cost green car (LCGC) distributed in Indonesia was taken as the material for the comparative study of tensile and impact strength. The bumper was cut and machined similar to the size of the RSF-reinforced composite specimen for testing purposes.

\section{B. Alkali Treatment of Rice Straw}

The RSF that underwent an alkali treatment process ( $\mathrm{RSFNaOH})$ was immersed in a $\mathrm{NaOH}$ solution at 5 wt.\% concentration for 2 hours at room temperature. The used concentration was adopted from the similar treatment of $\mathrm{NaOH}$ towards the same materials [27], [36]. The treated fibers were then rinsed with distilled water to remove the remainder of $\mathrm{NaOH}$ solution from the fiber surfaces. This was done until the $\mathrm{pH}$ of the washing water reached the normal range for distilled water. A drying process at $33{ }^{\circ} \mathrm{C}$ followed the process to reduce the moisture content and dry the fibers until the whole fibers reached their constant weight. For the RSF without $\mathrm{NaOH}$ treatment (RSFRaw), distilled water was used to replace the $\mathrm{NaOH}$ solution in the immersion process.

\section{Rice Straw Fiber Loading in Composite Fabrication}

A single cavity glass-mold with a dimension of $270 \mathrm{~mm} \times$ $50 \mathrm{~mm}$ was used for the preparation of test specimen. The RSF-reinforced composites were fabricated using hand layup and open-molding method. Four types of laminate with different RFS loadings of $10 \%, 20 \%, 30 \%$, and $40 \%$ volume fractions were generated based on the final laminate volume at $270 \mathrm{~mm} \times 50 \mathrm{~mm} \times \mathrm{t}$, where $\mathrm{t}$ was the designated thickness of laminate in $\mathrm{mm}$ unit. Volume fraction was selected overweight fraction because the former form considers the porosity factor resulted in the process of composite making [34]. The processes were initiated by coating the mold surface with a commercial mold-release agent (Mirror Glaze/MGH 8) until it was cured sufficiently. Each laminate was built of three different orientations of unidirectional lamina at $0^{\circ}, 45^{\circ}$, and $90^{\circ}$ that laid out manually with a curing process of $4 \mathrm{~h}$ at a normal room temperature and condition for each unidirectional lamina. The laminating resin was applied by using a paint roller to consolidate the laminate, thoroughly wetting the fibers, and removing the entrapped air. All layers of RSF were added to build the designated laminate thickness at $5 \mathrm{~mm}$ for the tensile test and $4 \mathrm{~mm}$ for the impact test specimens. Each cured laminate was cut to their respective standard dimensions for the tensile and impact strength tests.

\section{Characterization}

The fabricated RSF composites were characterized in terms of mechanical properties for their tensile and impact strength according to ASTM D638 for the tensile test and ASTM D256 for the impact test. A total of 5 replications for each test were performed at room temperature where the resulted data were analyzed for their mean values. The data 
were then compared against the obtained tensile and impact strength test resulted from a commercial standard automotive bumper material with the same ambient parameters and settings as the research specimens.

The tensile strength test used the five specimens by leaving them to break until the ultimate strength data can be observed. The specimen was shaped in a form of a dumbbell with an outer dimension of $250 \mathrm{~mm} \times 25 \mathrm{~mm} \times 5 \mathrm{~mm}$. Each of them was securely held by top and bottom grips to RME 300 Series Electromechanical Universal Test Machines. During the test, the grips are moved apart at a constant rate to pull and stretch the specimen until failure. The force and its displacement were then continuously monitored and plotted on a stress-strain curve, and the strength was calculated from the maximum load at failure of the tensile stress.

The impact strength of the samples was measured by the Izod impact tester for determining the impact resistance. The standard specimen for ASTM was used with a size of 127 $\mathrm{mm} \times 25 \mathrm{~mm} \times 4 \mathrm{~mm}$. The test specimen was supported as a vertical cantilever beam and broken by a single swing of a pendulum. The macro-examination on the physical structure of the composites cross-sectional area was conducted through a metallography test (WILD MPS Photo Macro), according to ASTM E340. Two metallographic specimens from the composites made of 30 and 40 volume $\%$ fiber loading were observed without specimens etching at the $6 \times$ and $12 \times$ magnifications.

\section{RESULTS AND DISCUSSION}

The mechanical test results indicated that the alkali treatment and fiber loading factors contributed to the variation of tensile and impact strengths of the composites. The increase in fiber loading suggested an increase in the strength of the mechanical properties up until one fixed point. Additional fiber loading beyond those points was leading to an opposite effect on the declining strength of the said properties. Further observations also revealed that the RSFreinforced composite has a sustainable strength over standard commercial bumper produced by the related car manufacturer. The ultimate tensile strengths for the RSFreinforced composites ranged from 5.55 $\mathrm{MPa}$ to $14.30 \mathrm{MPa}$ for the raw fibers and $6.99 \mathrm{MPa}$ to $14.75 \mathrm{MPa}$ for the alkalitreated sources. Meanwhile, the impact strength varied from $4.22 \mathrm{~J} \mathrm{~cm}-1$ to $18.08 \mathrm{~J} \mathrm{~cm}-1$ for the raw fiber-reinforced composites and $4.23 \mathrm{~J} \mathrm{~cm}-1$ to $23.52 \mathrm{~J} \mathrm{~cm}-1$ for the alkalitreated fiber-reinforced composites (Table 2).

\section{A. Ultimate Tensile Strength}

The alkali treatment with $\mathrm{NaOH}$ solution improved the ultimate tensile strength of the RSF-reinforced composites (Figure 1). This result was supported by other studies on the application of alkali treatment towards natural fibers [22], [23], [38]. The overall test results for the tensile strength revealed that the alkali-treated RSF-reinforced composites have always higher mean values compared to the raw RSFreinforced composites at all levels of fiber loading.

The raw RSF-reinforced composites' lowest tensile strength value was recorded at $5.55 \mathrm{MPa}$ at $40 \%$ fiber loading $(\mathrm{v} / \mathrm{v})$ while the highest value was observed at 14.30 $\mathrm{MPa}$ at $30 \%$ fiber loading (v/v). The alkali expressed the better tensile strength values treated RSF-reinforced composites with the lowest value of $6.99 \mathrm{MPa}$ at $10 \%$ fiber loading (v/v) and the highest value at $14.75 \mathrm{MPa}$ for $30 \%$ fiber loading (v/v) as shown in Table II. It was argued that the changes in fiber morphology and the chemical composition after an alkali treatment can affect the bonding mechanism efficiency between fibers and matrix, leading to better compatibility between them, and thus increasing the tensile strength [13], [39]. However, this is not to ignore the concentration factor involved in the treatment process, which may also affect the direction of the results [12], [22].

The increasing trend of the tensile strength values can be observed as they reached their maximum at $30 \%$ fiber loading (v/v) for both raw and alkali-treated RSF-reinforced composites. The values sharply declined at the next fiber loading level of $40 \%(\mathrm{v} / \mathrm{v})$ for both treatments. The increase of the tensile strength values until their maximum at $30 \%$ fiber loading for both raw and alkali-treated composites can be explained by the rule of mixture, where adding high strength fibers to a matrix with adequate interfacial bonding should result in increasing tensile strength of the composite up to an optimum value, where the value will then decrease with the keep growing content for fiber [6], [8], [9], [12], [13].

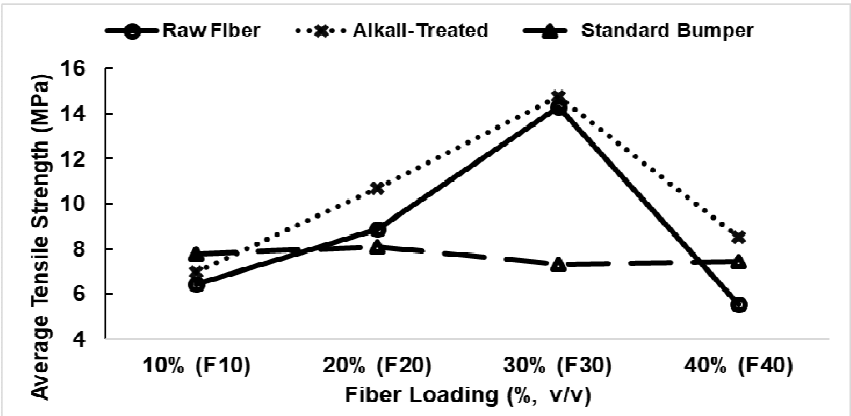

Fig. 1 Ultimate tensile strength exhibited by the RSF-reinforced composites at various fibre loadings.

It was also indicated that the alkali treatment has a correlation with the fiber loading factor [40]. Without alkali treatment, rice straw-reinforced composites tensile strength may decrease with the increasing of rice straw content. This could be rationalized by the poor surface interaction between the hydrophobic polymer chain and the hydrophilic rice straw surfaces where the hydrophilic rice straw cannot firmly adhere to the surface of the polymer chain and tend to agglomerate to each other at higher content.

Against the selected commercial bumper specimen, both RSF-reinforced composites exhibited higher mean tensile strength values at $20 \%$ and $30 \%$ (v/v) fiber loadings. Lower values were observed only for both raw and alkali-treated composites at $10 \%(\mathrm{v} / \mathrm{v})$ fiber loading, and the raw RSFreinforced composites at $40 \%(\mathrm{v} / \mathrm{v})$ fiber loading. The higher mean tensile strength values that went beyond the commercial bumper tensile strength provided a good indication that the right alkali treatment application and fiber loadings for the composites could result in a competitive outcome of bumper material tensile strength. The selective range of fiber content could really affect the interlocking mechanism where the matrix-to-fiber load transfer occurred. 
TABLE III

RESULTS SUMMARY OF THE ULTIMATE TENSILE STRENGTH AND IMPACT STRENGTH OF RSF-REINFORCED COMPOSITES

\begin{tabular}{|c|c|c|c|c|c|c|}
\hline \multirow[b]{2}{*}{ 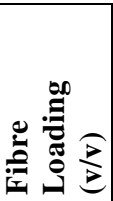 } & \multicolumn{3}{|c|}{ Tensile Strength (MPa) } & \multicolumn{3}{|c|}{ Impact Strength $\left(\mathrm{J} \mathrm{cm}^{-1}\right)$} \\
\hline & 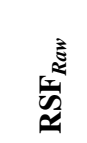 & 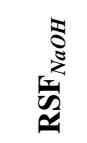 & 를 & 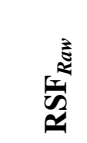 & 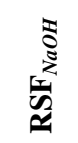 & 를 \\
\hline $10 \%$ & 6.43 & 6.99 & 7.80 & 8.51 & 4.23 & 19.28 \\
\hline $20 \%$ & 8.89 & 10.69 & 8.09 & 12.16 & 12.12 & 22.79 \\
\hline $30 \%$ & 14.30 & 14.75 & 7.31 & 18.08 & 23.52 & 23.31 \\
\hline $40 \%$ & 5.55 & 8.54 & 7.43 & 4.22 & 10.85 & 19.9 \\
\hline
\end{tabular}

This is supported by Abishek et al. [41] in the application of jute fiber for bumper beam application, where the fiber loading factor essentially administered the resulted tensile strength.

\section{B. Impact Strength}

The impact test results showed variations over the expressed mean impact strength values from both raw and alkali-treated composites. The values were higher for the alkali-treated composites at $30 \%$ and $40 \%$ (v/v) fiber loadings compared to the raw RSF-reinforced composites. However, lower values were observed at $10 \%$ and $20 \%(\mathrm{v} / \mathrm{v})$ fiber loadings for the same alkali-treated composites (Figure $2)$.

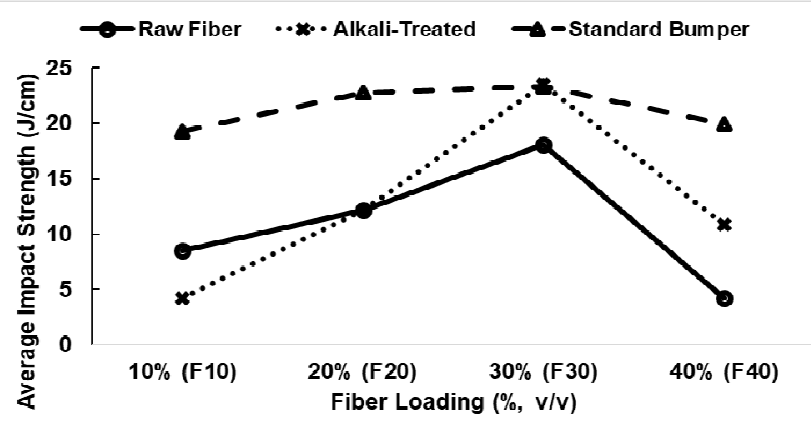

Fig. 2 Impact strength exhibited by the RSF-reinforced composites at various fibre loadings.

The highest mean impact strength value for raw RSFreinforced composites was recorded at $18.08 \mathrm{~J} \mathrm{~cm}-1$ from the $30 \%(\mathrm{v} / \mathrm{v})$ fiber loading variable, while the lowest value was recorded at $4.22 \mathrm{~J} \mathrm{~cm}-1$ from the $40 \%(\mathrm{v} / \mathrm{v})$ fiber loading variable. The alkali-treated composites provided a wider range of impact strength values with a maximum point at $23.52 \mathrm{~J} \mathrm{~cm}-1$ for $30 \%$ fiber loading composites and minimum point at $4.23 \mathrm{~J} \mathrm{~cm}-1$ for $10 \%$ fiber loading composites. A comparative study by Alavudeen et al. [39] agreed upon where an alkali treatment promotes adhesion between the fibers and the matrix, thus improving the impact strength. Based on the study, the impact strength of untreated composites is $23 \mathrm{~kJ} \mathrm{~m}-2$, whereas the alkali-treated composites were improved to $26 \mathrm{~kJ} \mathrm{~m}-2$.

Despite the intertwined results between the raw and alkali-treated RSF-reinforced composites, the variations in fiber loading presented a similar trend with the increase of mean test values as the loading reached $30 \%$ volume fractions, followed by sharp declines as the fiber added to
$40 \%$ volume fractions. This can be probably attributed to the increase in the stiffness of the composites by the increase of fiber content [42]. Several studies showed that different material selection and fiber loading may result in the variation of impact strength [14, 42]. It was shown that not only the impact strength has an opposite trend from the tensile strength, but also that the increase in fiber loading resulted in the lower value of impact strength.

In comparison with the selected commercial, automotive bumper, the overall mean of impact strength values appeared to be lower than the values of the commercial bumper. The only point where the impact strength value can reach similar to the standard bumper impact strength value was when the alkali-treatment was applied for the $30 \%(\mathrm{v} / \mathrm{v})$ fiber loading composites. However, this could still be taken as a good indication that the appropriate adjustment in alkali treatment application and fiber loading can give a comparable result against a commercial bumper beam.

\section{Microstructure Analysis}

The composition and the presence of voids can be observed from the sectional cutting view of the composites with different fiber loadings. The microstructure observation based on the metallographic techniques revealed that all composites from 10 to $40 \%$ fiber loadings were prone to voids (Figure 3 ).
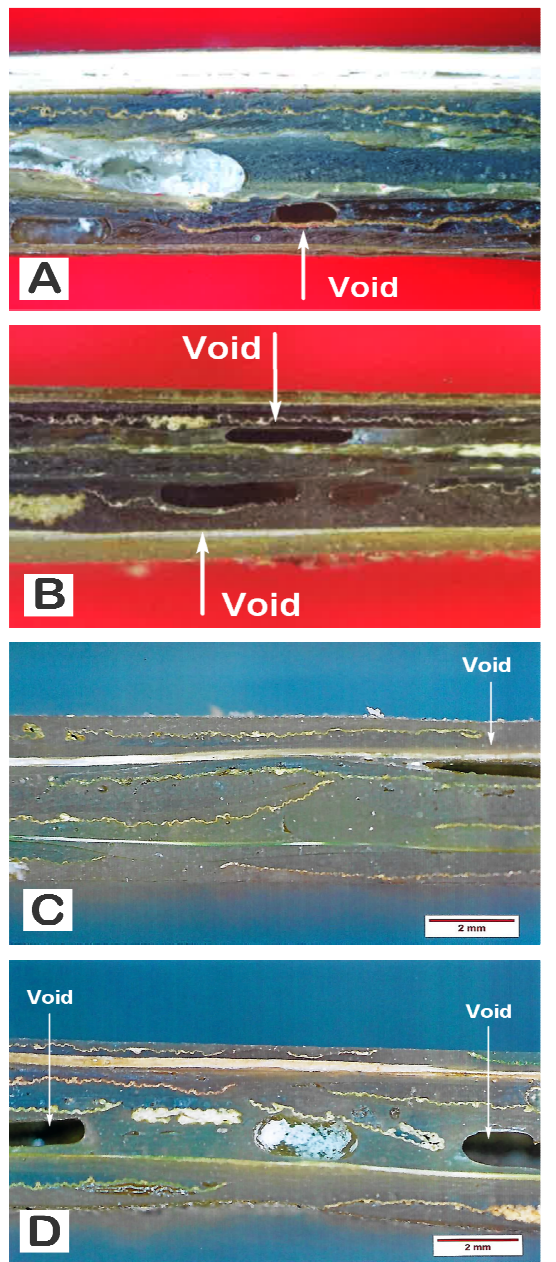

Fig. 3 Cross-sectioned microscopic structure of the RSF-reinforced polymer composite at $10 \%$ (A), $20 \%$ (B), $30 \%$ (C) and $40 \%$ (D) fibre loading $\left(\mathrm{RSF}_{\mathrm{NaOH}}\right)$. 
It is observed that the composites with 20 and $40 \%$ fiber loadings have a broader and higher number of voids. Regardless, voids from all range of fiber loadings seemed to be located at similar positions relative to the lamina. This is possibly due to the changing resin flow dynamics as the fiber content increased. A comparative result was reported [43] on the making of fiber composites from plant fiber. It was hypothesized that the increase in the fiber volume fractions of yarn composites was followed by the increased number of voids between the adjacent yarns. Despite the seemingly higher number of voids occurrence as the fiber content increased, there is no clear correlation between the fiber loading factor and porosity.

\section{CONCLUSIONS}

The right application of alkali treatment with sodium hydroxide was proven to give an improvement in the tensile and impact strength of the RSF-reinforced composites. It was observed as well that fiber loading provided a variation towards the mechanical properties of the composites, where $30 \%(\mathrm{v} / \mathrm{v})$ fiber loading led to the maximum observable values of the composite tensile strength and impact strength. In reference to the comparative result of the mechanical properties, the rice straw fiber, at $30 \%$ fiber loading coupled with the alkali treatment, can be used as an alternative material to reinforce a polymer composite for automotive bumper application with a competitive tensile and impact strength against a commercial bumper available in the market. For this specific study, the 30\% RSF fiber loading coupled with the alkali treatment was proven to have a better and competitive result in car bumper application The result of this study can be used as a reference for the further research and development in the application of natural fibers as an alternative material for composites, particularly for the bumper production in the automotive industry.

\section{ACKNOWLEDGMENT}

The authors wish to express their gratitude to the Secretary of Research and Higher Education, Republic of Indonesia, for their support through Hibah Penelitian Produk Terapan fiscal of the year 2017-2018 with contract number 0409/K3/KM/2017.

\section{REFERENCES}

[1] U. S. Bongarde and V. D. Shinde, Review on natural fiber reinforcement polymer composites, Int. J. Eng. Sci. Innov. Technol., vol. 3, pp. 431-436, 2014.

[2] F. Omar, B. A. K., F. Hans Peter, and S. Mohini, Progress Report on Natural Fiber Reinforced Composites, Macromol. Mater. Eng., vol. 299, no. 1, pp. 9-26, 2013.

[3] P. J. Herrera-Franco and A. Valadez-González, A study of the mechanical properties of short natural-fiber reinforced composites, Compos. Part B Eng., vol. 36, no. 8, pp. 597-608, 2005.

[4] J. Holbery and D. Houston, Natural-fiber-reinforced polymer composites in automotive applications, JOM, vol. 58, no. 11, pp. 8086, Nov. 2006.

[5] X. Li, L. G. Tabil, and S. Panigrahi, Chemical Treatments of Natural Fiber for Use in Natural Fiber-Reinforced Composites: A Review, J. Polym. Environ., vol. 15, no. 1, pp. 25-33, Jan. 2007.

[6] H. Ku, H. Wang, N. Pattarachaiyakoop, and M. Trada, A review on the tensile properties of natural fiber reinforced polymer composites, Compos. Part B Eng., vol. 42, no. 4, pp. 856-873, 2011.

[7] S. V Joshi, L. T. Drzal, A. K. Mohanty, and S. Arora, Are natural fiber composites environmentally superior to glass fiber reinforced composites?, Compos. Part A Appl. Sci. Manuf., vol. 35, no. 3, pp. 371-376, 2004.

[8] A. Furqan, C. H. Soap, and P. M. Kyun, A Review: Natural Fiber Composites Selection in View of Mechanical, Light Weight, and Economic Properties, Macromol. Mater. Eng., vol. 300, no. 1, pp. 10-24, 2014.

[9] F. M. AL-Oqla and S. M. Sapuan, Natural fiber reinforced polymer composites in industrial applications: feasibility of date palm fibers for sustainable automotive industry, J. Clean. Prod., vol. 66, pp. 347-354, 2014.

[10] N. M. Azzmi and J. M. Yatim, "Kenaf Fibrous Concrete: Mechanical Properties with Different Fiber Volume Fraction," vol. 8, no. 4, pp. 1036-1042, 2018

[11] H. M. Naguib, U. F. Kandil, A. I. Hashem, and Y. M. Boghdadi, Effect of fiber loading on the mechanical and physical properties of green' bagasse-polyester composite, J. Radiat. Res. Appl. Sci., vol.8, no. 4, pp. 544-548, 2015.

[12] E. Rojo, M. V. Alonso, M. Oliet, B. Del Saz-Orozco, and F. Rodriguez, Effect of fiber loading on the properties of treated cellulose fiber-reinforced phenolic composites, Compos. Part B Eng., vol. 68, pp. 185-192, 2015.

[13] M. N. Akhtar et al., Influence of alkaline treatment and fiber loading on the physical and mechanical properties of kenaf/polypropylene composites for variety of applications, Prog. Nat. Sci. Mater. Int., vol. 26, no. 6, pp. 657-664, 2016.

[14] M. F. Zafar and M. A. Siddiqui, Raw natural fiber reinforced polystyrene composites: Effect of fiber size and loading, Mater. Today Proc., vol. 5, no. 2, Part 1, pp. 5908-5917, 2018.

[15] P. V. C. R. K. Santosha, A. S. S. S. Gowda, and V. Manikanth, "Effect of fiber loading on thermal properties of banana and pineapple leaf fiber reinforced polyester composites, Mater. Today Proc., vol. 5, no. 2, Part 1, pp. 5631-5635, 2018.

[16] N. Graupner, G. Ziegmann, F. Wilde, F. Beckmann, and J. Müssig, "Procedural influences on compression and injection moulded cellulose fibre-reinforced polylactide (PLA) composites: Influence of fibre loading, fibre length, fibre orientation and voids, Compos. Part A Appl. Sci. Manuf., vol. 81, pp. 158-171, 2016.

[17] M. Jacob and A. R. D., Recent developments in chemical modification and characterization of natural fiber reinforced composites, Polym. Compos., vol. 29, no. 2, pp. 187-207.

[18] A. Zulfia, K. Raga, W. Narottama, and S. Yunus, "Al6061 Reinforced Al2O3 Metal Matrix Composite Produced by Double Blade Stir Casting," vol. 9, no. 5, pp. 1544-1549, 2019.

[19] B. A. Budiman, F. B. Juangsa, M. Aziz, and I. P. Nurprasetio, "Experimental Verification of Interfacial Strength Effect on the Mechanical Properties of Carbon Fiber-Epoxy Composite Experimental Verification of Interfacial Strength Effect on the Mechanical Properties of Carbon Fiber-Epoxy Composite," no. January 2018, 2017

[20] G. Bochmann, 4-Storage and feedstock preparation, in Substitute Natural Gas from Waste, 2019.

[21] Z. Guangyin and Z. Youcai, Harvest of Bioenergy from Sewage Sludge by Anaerobic Digestion, in Pollution Control and Resource Recovery from Sewage Sludge, 2017.

[22] M. Cai, H. Takagi, A. N. Nakagaito, Y. Li, and G. I. N. Waterhouse, Effect of alkali treatment on interfacial bonding in abaca fiber reinforced composites, Compos. Part A Appl. Sci. Manuf., vol. 90, pp. 589-597, 2016.

[23] A. Gopinath, M. Senthil Kumar, and A. Elayaperumal, Experimental Investigations on Mechanical Properties Of Jute Fiber Reinforced Composites with Polyester and Epoxy Resin Matrices, Procedia Eng., vol. 97, pp. 2052-2063, 2014.

[24] Y. Wu, C. Xia, L. Cai, A. C. Garcia, and S. Q. Shi, "Development of natural fiber-reinforced composite with comparable mechanical properties and reduced energy consumption and environmental impacts for replacing automotive glass-fiber sheet molding compound," J. Clean. Prod., vol. 184, pp. 92-100, 2018.

[25] Mahyoedin, Yovial, J. Sahari, A. Mukhtar, and N. Mohammad, Effect of graphite sizes and carbon black content on flowability of the injection molded conductive composite material, in MATEC Web of Conferences, vol. 248, p. 01007. EDP Sciences, 2018.

[26] F. Yao, Q. Wu, Y. Lei, and Y. Xu, Rice straw fiber-reinforced highdensity polyethylene composite: Effect of fiber type and loading, Ind. Crops Prod., vol. 28, no. 1, pp. 63-72, 2008.

[27] M. R. Ismail, A. A. M. Yaseen, and M. S. Afify, Mechanical properties of rice straw fiber-reinforced polymer composites, Fibers Polym., vol. 12, no. 5, pp. 648-656, 2011. 
[28] J. Liu, C. Jia, and C. He, Rice Straw and Cornstarch Biodegradable Composites, AASRI Procedia, vol. 3, pp. 83-88, 2012.

[29] E. Jayamani, S. Hamdan, M. R. Rahman, and M. K. Bin Bakri, Study of Sound Absorption Coefficients and Characterization of Rice Straw Stem Fibers Reinforced Polypropylene Composites, Bioresour. Vol 10, No 2, 2015.

[30] X. Xie, Z. Zhou, M. Jiang, X. Xu, Z. Wang, and D. Hui, Cellulosic fibers from rice straw and bamboo used as reinforcement of cementbased composites for remarkably improving mechanical properties, Compos. Part B Eng., vol. 78, pp. 153-161,

[31] Suherman, Hendra, Y. Mahyoedin, E. Septe, and R. Rizade. Properties of graphitelepoxy composites: the in-plane conductivity, tensile strength and Shore hardness, 2019.

[32] J. H. Low, N. Andenan, W. A. W. A. Rahman, R. Rusman, and R. A. Majid, Evaluation of Rice Straw as Natural Filler for Injection Molded High Density Polyethylene Bio-composite Materials, Chem. Eng. Trans., vol. 56, pp. 1081-1086, 2017.

[33] M. Al Amin, M. Rafiquzzaman, M. Ariful Alam, R. Ahmed Rahat, and R. Ahasan, Optimization of Design Parameters for Achieving Highest Impact Strength of Rice straw Based Polymer Composite Using Taguchi Method, Int. J. Emerg. Eng. Res. Technol., vol. 5, pp. 22-29, 2017.

[34] R. Bakker, W. Elbersen, R. Poppens, and J. P. Lesschen, Rice Straw and Wheat Straw: Potential feedstocks for the biobased economy, 2013

[35] M. Bouasker, N. Belayachi, D. Hoxha, and M. Al-Mukhtar, Physical characterization of natural straw fibers as aggregates for construction materials applications, Materials (Basel)., vol. 7, pp. 3034-3048, 2014
[36] S. Harun and S. K. Geok, Effect of sodium hydroxide pretreatment on rice straw composition, Indian J. Sci. Technol., vol. 9, no. 21, pp. $1-9,2016$.

[37] K. Abe and H. Yano, Comparison of the characteristics of cellulose microfibril aggregates of wood, rice straw and potato tuber, Cellulose, vol. 16, no. 6, p. 1017, Jun. 2009.

[38] V. Fiore, G. Di Bella, and A. Valenza, The effect of alkaline treatment on mechanical properties of kenaf fibers and their epoxy composites, Compos. Part B Eng., vol. 68, pp. 14-21, 2015

[39] A. Alavudeen, N. Rajini, S. Karthikeyan, M. Thiruchitrambalam, and N. Venkateshwaren, Mechanical properties of banana/kenaf fiber reinforced hybrid polyester composites: Effect of woven fabric and random orientation, Mater. Des., vol. 66, pp. 246-257, 2015

[40] J. H. Low, N. Andenan, and W. A. W. A. Rahman, The Influence of Crosslink Chemicals on the Mechanical Strength and Water Absorption of Rice Straw-Based Green Composites, J. Nat. Fibers, vol. 15, no. 1, pp. 122-130, 2018.

[41] M. R. Abishek, P. M. Suresh, and H. S. Sreedhar Murthy, Evaluation of mechanical properties of Jute/E-Glass epoxy hybrid composites by varying fibre loading with and without shear thickening fluid," Mater. Today Proc., vol. 4, pp. 10858-10862, 2017

[42] Y. A. El-Shekeil, S. M. Sapuan, and M. W. Algrafi, Effect of fiber loading on mechanical and morphological properties of cocoa pod husk fibers reinforced thermoplastic polyurethane composites, Mater. Des., vol. 64, pp. 330-333, 2014.

[43] D. U. Shah, P. J. Schubel, P. Licence, and M. J. Clifford, Determining the minimum, critical and maximum fibre content for twisted yarn reinforced plant fibre composites, Compos. Sci. Technol., vol. 72, no. 15, pp. 1909-1917, 2012. 